\title{
Biologia de Bemisia tabaci (Genn.) biótipo B (Hemiptera: Aleyrodidae) em genótipos de tomateiro em duas épocas
}

\author{
Luciana Claudia Toscano ${ }^{1}$, Arlindo Leal Boiça Junior ${ }^{2}$, Gustavo Luís Mamoré Martins ${ }^{1}$, \\ Wilson Itamar Maruyama ${ }^{1}$ \\ ${ }^{1}$ Universidade Estadual de Mato Grosso do Sul - UEMS, Unidade Universitária de Cassilândia, Cassilândia, Mato Grosso do Sul,
Brasil. E-mail: toscano@ uems.br, gustavomamore@ yahoo.com.br, wilsonmaruyma@uems.br
${ }^{2}$ Universidade Estadual Paulista Júlio de Mesquita Filho - UNESP, Jaboticabal, São Paulo, Brasil. E-mail: aboiajr@ fcav.unesp.br
}

Recebido: 12/05/2016; Aceito: 05/07/2016.

\section{RESUMO}

Bemisia tabaci biótipo B é, atualmente, uma das mais importantes pragas da cultura do tomate. Este trabalho teve o objetivo de estudar a biologia da praga em genótipos de tomateiro em duas épocas. $\mathrm{O}$ ensaio foi conduzido em casa-de-vegetação instalada na área experimental do Departamento de Fitossanidade, da FCAV/Unesp, Jaboticabal. Foram utilizados os genótipos comerciais, híbrido Bruna VFN e Santa Clara e exóticos, LA 716, PI 134417, PI 127826 e PI 127827 em duas épocas diferentes, “inverno" e "primavera". O período de incubação variou de 12,11 dias (PI 134417) a 13,85 dias (LA 716). O período ninfal variou de 21,12 dias (PI 127827) a 22,56 dias (híbrido Bruna VFN). O período total de desenvolvimento variou de 37,31 dias (híbrido Bruna VFN) a 34,48 dias (PI 127827). A longevidade dos adultos foi maior para os insetos provenientes do genótipo exótico PI 127826 (1,5 dias), que diferiu significativamente dos demais genótipos, os quais apresentaram longevidade variando de 1,00 a 1,10 dias. O período total de desenvolvimento foi de 35,92 na época "de inverno" e 15,89 dias na época "de primavera". Desse modo, o ciclo do inseto foi 2,26 vezes maior na época de "inverno" em relação à da "primavera", evidenciando ser esta última a mais apropriada ao desenvolvimento da praga.

Palavras-chave: Lycopersicon, mosca-branca, resistência de plantas.

\section{Biology of Bemisia tabaci (Genn.) biotype B (Hemiptera: Aleyrodidae) in tomato genotypes in two seasons}

\begin{abstract}
Bemisia tabaci biotype B is currently one of the most important pests of tomato crop. This work aimed to study the pest biology in tomato genotypes in two seasons. The test was conducted in a greenhouse in the experimental area of the Plant Protection Department of the FCAV/UNESP, Jaboticabal, SP, Brazil. Two commercial genotypes (hybrid Bruna VFN and Santa Clara) and four exotic genotypes (LA 716, PI 134417, PI 127826 and PI 127827) were used in two different seasons, "winter" and "spring". The incubation period ranged from 12.11 days (PI 134417) to 13.85 days (LA 716). The nymphal period ranged from 21.12 days (PI 127827) to 22.56 days (hybrid Bruna VFN). Total development period ranged from 37.31 days (hybrid Bruna VFN) to 34.48 days (PI 127827). Adult longevity was higher for insects from the exotic genotype PI 127826 (1.5 days), which differed significantly from the other genotypes, which showed longevity ranging from 1.00 to 1.10 days. The total period of development was 35.92 at the time "winter" and 15.89 days in season "spring". Thus, the insect cycle was 2.26 times greater at the "winter" in relation to the "spring", demonstrating the latter being more suitable for the development of the pest.
\end{abstract}

Key words: Lycopersicon, white fly, plants resistance. 


\section{Introdução}

Dentre as hortaliças, o tomateiro é a cultura mais importante, não só em termos de produção como também em valor econômico, pois, é a mais industrializada (FILGUEIRA, 2008). O Brasil produziu 4.145.553 toneladas de tomate em uma área de 62.050 hectares, em 2015. A estimativa para a safra de 2016 é que a região Centro-Oeste tenha uma produção de 687.785 toneladas (IBGE, 2016).

Essa cultura, no entanto, é muito sujeita ao ataque de pragas, sendo os gastos com controle variável conforme a região, época de plantio e incidência de insetos. Dentre as pragas que atacam o tomateiro, a moscabranca Bemisia tabaci biótipo B (Hemiptera: Aleyrodidae) mereceu destaque nos últimos anos (LOURENÇÃO; NAGAI, 1994).

O gênero Bemisia destaca-se como praga importante do tomateiro após o surgimento do biótipo B que também foi descrito como Bemisia argentifolii. No Brasil, o biótipo B foi introduzido na década de 90, sendo observadas plantas atacadas no Distrito Federal. $\mathrm{Na}$ cultura do tomate os danos causados pela moscabranca podem ser diretos e indiretos. (LOURENÇÃO; NAGAI, 1994).

Os prejuízos diretos estão relacionados à sucção de seiva e injeção de toxinas, que provoca o amadurecimento irregular dos frutos que se tornam internamente esbranquiçados e com aspecto esponjoso. A liberação de uma substância açucarada (honeydew) provoca a proliferação do fungo Capnodium sp. (fumagina), o que diminui a área fotossintética da planta e, consequentemente, sua produtividade (CARVALHO et al., 2015).

Os danos indiretos são relacionados à transmissão de geminivírus, causando geralmente clorose entre as nervuras na base do folíolo que evolui para um mosaico-amarelo, sintomas que se generalizam por toda a planta e são seguidos por intensa rugosidade dos folíolos. Para a elaboração de estratégias de manejo do vetor na cultura do tomate é importante o conhecimento sobre a biologia da praga (VILLAS BOAS et al., 1997).

As pesquisas sobre biologia de mosca branca em tomateiro evidenciam que há variação nos resultados encontrados, em função da resistência de genótipos de tomateiro (FANCELLI et al., 2003) e das condições climáticas que podem variar nas diferentes épocas do ano (VILLAS-BOAS et al., 2002; BALDIN et al., 2005).

Desse modo, devido à grande importância da moscabranca na cadeia produtiva do tomate, o presente trabalho objetivou estudar a biologia de $B$. tabaci biótipo $\mathrm{B}$ em genótipos de tomateiro, em duas épocas “inverno" e "primavera".

\section{Material e Métodos}

O ensaio em casa-de-vegetação $(5,0 \times 10,5 \mathrm{~m})$ instalada na área experimental do Departamento de Fitossanidade, da Faculdade de Ciências Agrárias e Veterinárias, Unesp, Campus de Jaboticabal.

A criação de B. tabaci biótipo B foi conduzida a partir de populações obtidas do Centro de Fitossanidade, setores de Virologia e Entomologia, do Instituto Agronômico de Campinas (IAC), identificada como $B$. tabaci biótipo B. Para a alimentação dos insetos foram oferecidas plantas de brócolos, couve, soja, abóbora e poinsétia.

Foram adquiridos genótipos de tomateiro no banco de germoplasma da Embrapa Hortaliças (Brasília, DF). A semeadura dos genótipos foi realizada em bandeja de poliestireno expandido contendo substrato agrícola, e o transplantio realizado em vasos plásticos com 3 litros de capacidade, contendo três partes de solo, uma de areia e uma parte de composto orgânico. A adubação dos vasos foi realizada de acordo com a análise de solo, dentro dos níveis recomendados para a cultura (FILGUEIRA, 2008): adubação de base: $1,5 \mathrm{~g}$ de superfosfato simples, $0,3 \mathrm{~g}$ de cloreto de potássio, $0,3 \mathrm{~g}$ de nitrato de amônio por kg de solo; adubação de cobertura: $0,3 \mathrm{~g}$ de nitrato de amônio por $\mathrm{kg}$ de solo (aos 15 dias após o transplantio) e $0,3 \mathrm{~g}$ de nitrato de amônio por $\mathrm{kg}$ de solo (aos 25 dias após o transplantio).

Quando as plantas estavam com 30 dias de idade foram infestadas por 100 adultos/planta e, após 24 horas de infestação, os insetos foram retirados. Com auxílio de lupa de bolso (aumento de 20x), contou-se o número de ovos de mosca-branca contidos em uma planta de cada genótipo de tomateiro. Cada folíolo foi etiquetado com o número de ovos presentes, sendo o mínimo de dez e o máximo de vinte por planta, totalizando cinco plantas por genótipo. Estes ovos estavam situados na página inferior da folha e seu excesso foi eliminado através de um estilete. Acompanhou-se o desenvolvimento de cada um dos ovos até a fase adulta. Diariamente e no mesmo horário, anotou-se o número de ovos, ninfas e adultos emergidos.

$\mathrm{O}$ experimento foi conduzido em delineamento de blocos casualizados com seis tratamentos (genótipos) e cinco repetições (plantas). Amostragens sobre a biologia de B. tabaci biótipo B foram realizadas nos genótipos comerciais, híbrido Bruna VFN e Santa Clara (Lycopersicon esculentum Mill.) e nos exóticos, LA 716 (Lycopersicon pennellii (Correll) D'Arcy), PI 134417 (Lycopersicon hirsutum f. glabratum C. H. Mull.), PI 127826 e PI 127827 (Lycopersicon hirsutum Dunal) em duas épocas diferentes, no "inverno" com início dos experimentos em 07/07/2000, e na "primavera" iniciando em 12/10/2000.

Foram avaliados os seguintes parâmetros: período de incubação (dias), período ninfal (dias), período total de 
desenvolvimento (dias), porcentagem de eclosão de ninfas (\%), porcentagem de mortalidade de ninfas (\%) e longevidade de adultos (dias). O último parâmetro foi considerado desde o momento da emergência até a morte de cada indivíduo, observada diariamente. À medida que foi ocorrendo a emergência, cada adulto foi transferido para frascos individuais de vidro transparentes $(3,6 \mathrm{~mL})$ totalizando dez adultos emergidos de cada material, mantidos em B.O.D, regulada à temperatura de $26 \pm 2{ }^{\circ} \mathrm{C}$, fotofase de 12 horas e umidade relativa de $70 \pm 5 \%$, sem alimentação.

Os dados foram submetidos à análise de variância através do teste $\mathrm{F}$ e as médias comparadas pelo teste de Tukey a $5 \%$ de probabilidade.

\section{Resultados e Discussão}

Resultados encontrados no ensaio para a biologia de B. tabaci biótipo B em genótipos de tomateiro na época "de inverno" (Tabela 1) evidenciou que o período de incubação variou de 12,1 dias (PI 134417) a 13,9 dias (LA 716), não ocorrendo diferença entre os genótipos.
O período ninfal variou de 21,1 dias (PI 127827) a 22,6 dias (híbrido Bruna VFN), valores que também não diferiram entre si; portanto, nenhum dos genótipos afetou o período de desenvolvimento das ninfas (Tabela 1). Oriane et al. (2008) também não verificaram diferenças no período ninfal de B. tabaci Biótipo B em ninfas criadas em genótipos de feijoeiro. Para o período total de desenvolvimento dos insetos, verificou-se também que não houve diferença significativa entre os genótipos, variando de 37,3 dias (híbrido Bruna VFN) a 34,5 dias (PI 127827) (Tabela 1). Esses valores são superiores aos encontrados por Oriane et al. (2008) que observaram o período total de desenvolvimento da praga variando de 21,0 a 26,5 dias em genótipos de feijoeiro, indicando que o tomate é mais favorável ao desenvolvimento dos insetos. A porcentagem de eclosão das ninfas foi $100 \%$ nos seis genótipos de tomateiro, não havendo diferenças significativas (Tabela 2).

A porcentagem de eclosão de ninfas de moscabranca geralmente é alta, podendo variar de $92 \%$ em temperatura de $27{ }^{\circ} \mathrm{C}$ a $99 \%$ em $30{ }^{\circ} \mathrm{C}$ (FANCELLI; VENDRAMIN, 2002).

Tabela 1. Períodos ( \pm EP) de incubação, ninfal e total de desenvolvimento de B. tabaci biótipo B, em seis genótipos de tomateiro, em ensaio de não-preferência para alimentação e/ou antibiose, na época "de inverno". Jaboticabal-SP.

\begin{tabular}{lccc}
\hline Genótipos & $\begin{array}{c}\text { Período de incubação } \\
(\text { dias })\end{array}$ & $\begin{array}{c}\text { Período ninfal } \\
(\text { dias })\end{array}$ & $\begin{array}{c}\text { Período total de } \\
\text { desenvolvimento (dias) }\end{array}$ \\
\hline LA 716 & $13,9 \pm 0,5 \mathrm{a}^{1,2}$ & $21,6 \pm 0,7 \mathrm{a}^{1,2}$ & $37,1 \pm 0,7 \mathrm{a}^{1,2}$ \\
Híbrido Bruna VFN & $13,4 \pm 0,8 \mathrm{a}$ & $22,6 \pm 0,4 \mathrm{a}$ & $37,3 \pm 0,9 \mathrm{a}$ \\
Santa Clara & $13,3 \pm 0,4 \mathrm{a}$ & $21,8 \pm 0,4 \mathrm{a}$ & $36,1 \pm 0,4 \mathrm{a}$ \\
PI 127826 & $12,8 \pm 0,3 \mathrm{a}$ & $21,2 \pm 1,2 \mathrm{a}$ & $34,9 \pm 1,3 \mathrm{a}$ \\
PI 127827 & $12,6 \pm 0,5 \mathrm{a}$ & $21,1 \pm 0,9 \mathrm{a}$ & $34,5 \pm 1,3 \mathrm{a}$ \\
PI 134417 & $12,1 \pm 2,2 \mathrm{a}$ & $22,4 \pm 0,9 \mathrm{a}$ & $35,6 \pm 1,1 \mathrm{a}$ \\
\hline \multicolumn{1}{c}{ F } & $1,50^{\mathrm{NS}}$ & $0,53^{\mathrm{NS}}$ & $1,28^{\mathrm{NS}}$
\end{tabular}

1. Médias seguidas pela mesma letra não diferem significativamente a $5 \%$ de probabilidade pelo teste de Tukey. ${ }^{2 .}$ Dados originais; (sem transformação).

Tabela 2. Porcentagem de eclosão e mortalidade de ninfas, longevidade de adultos de B. tabaci biótipo B, em seis genótipos de tomateiro, em ensaio de não-preferência para alimentação e/ou antibiose, na época "de inverno". Jaboticabal-SP.

\begin{tabular}{lccc}
\hline Genótipos & $\begin{array}{c}\text { Porcentagem de eclosão } \\
\text { de ninfas }(\%)\end{array}$ & $\begin{array}{c}\text { Porcentagem de mortalidade } \\
\text { de ninfas }(\%)\end{array}$ & $\begin{array}{c}\text { Longevidade de adultos } \\
\text { (dias) }\end{array}$ \\
\hline LA 716 & 100 & 7,0 & $1,0 \mathrm{~b}$ \\
Híbrido Bruna VFN & 100 & 0,0 & $1,0 \mathrm{~b}$ \\
Santa Clara & 100 & 0,0 & $1,0 \mathrm{~b}$ \\
PI 127826 & 100 & 0,0 & $1,5 \mathrm{a}$ \\
PI 127827 & 100 & 10,0 & $1,1 \mathrm{~b}$ \\
PI 134417 & 100 &, 3 & $1,0 \mathrm{~b}$ \\
\hline \multicolumn{1}{c}{ CV $(\%)$} & -- & $0,90^{\mathrm{NS}}$ & $6,35^{* *}$ \\
\end{tabular}

${ }^{1 .}$ Médias seguidas pela mesma letra não diferem significativamente a $5 \%$ de probabilidade pelo teste de Tukey. ${ }^{2 .}$ Dados originais; para a análise estatística foram transformados em arc sen $(x+0,5)$. 
A porcentagem de mortalidade de ninfas nos seis genótipos de tomateiro variou de $0,0 \%$ a $10,0 \%$, porém essas taxas foram baixas e não diferiram significativamente (Tabela 2). Possivelmente, após a eclosão algumas ninfas, na tentativa de se fixarem para alimentação nos tecidos da planta tenham ficado presas em tricomas glandulares e posteriormente morreram ou caíram do folíolo. Fancelli e Vendramim (2002) verificaram que a mobilidade de ninfas eclodidas em folíolos de LA 716 e PI 134417 quando na presença de exsudatos, esteve em torno de 50 e $10 \%$, respectivamente.

A longevidade dos adultos de B. tabaci biótipo B foi maior nos insetos provenientes do genótipo exótico PI 127826 (1,5 dias), que diferiu dos demais genótipos, os quais apresentaram longevidade variando de 1,0 a 1,1 dias (Tabela 2). Especula-se que, o PI 127826 deva possuir uma constituição de nutrientes mais equilibradas em relação aos demais, o que garante uma longevidade maior dos indivíduos sem alimentação. Esses valores de longevidade de adultos são semelhantes aos observados por Peixoto e Boiça Júnior (2014) onde não houve diferenças na longevidade de B. tabaci Biótipo B entre genótipos de feijoeiro em que a menor duração foi de 1,1 dias e a maior 1,5 dias.

Em relação aos parâmetros da biologia de B. tabaci biótipo B na época "de primavera" (Tabela 3), o período de incubação variou de 5,0 dias (Santa Clara) a 6,1 dias (LA 716), não se verificou diferenças entre os materiais. Para o período ninfal também não evidenciou diferença, variando de 9,5 dias a 11,4 dias. Quanto ao período total de desenvolvimento, constatou-se que houve diferença entre os genótipos, com o período mais longo sendo observado em LA 716 (17,5 dias) em relação aos genótipos Santa Clara e PI 127826 (15,3 e 15,0 dias).
Os demais genótipos permaneceram com comportamento intermediário (Tabela 3).

Mesmo que o LA 716 tenha aumentado o período total de desenvolvimento da praga, nas condições de primavera (Tabela 3), é possível que esse genótipo possua efeito antibiótico sobre a população da moscabranca. Para esse material (LA-716), Baldin et al. (2005) observaram que as moscas-brancas ficaram aderidas aos folíolos das plantas, devido à presença de exsudatos produzidos pelos tricomas glandulares. Essas estruturas, de acordo com Fancelli et al. (2003), configuram-se entre as mais significativas fontes de resistência mecânica desse material, uma vez que, ao reterem os insetos, estes acabam morrendo antes de ovipositarem ou transmitirem viroses às plantas.

Durante o desenvolvimento da mosca-branca na época "de primavera", verificou-se que a porcentagem de eclosão de ninfas foi $100 \%$ e não ocorreu mortalidade durante o período ninfal, resultados semelhantes à época "de inverno", quando a mortalidade de ninfas foi muito pequena. Os resultados do presente trabalho diferem dos encontrados por Fancelli e Vendramin (2002), que observaram valores de viabilidade dos ovos de $88,12 \%$ para cultivar Santa Clara e a viabilidade ninfal, em geral, extremamente baixa.

Comparando-se os parâmetros biológicos de $B$. tabaci biótipo $\mathrm{B}$ nos seis genótipos de tomateiro nas duas épocas, (Figura 1), observou-se que todos os resultados de período de desenvolvimento das diferentes fases do inseto foram maiores na condição de inverno em relação à primavera, confirmando resultados que evidenciam que a temperatura e umidade do ambiente influenciaram a biologia do inseto.

Tabela 3. Períodos ( \pm EP) de incubação, ninfal e total de desenvolvimento de B. tabaci biótipo B, em seis genótipos de tomateiro, em ensaio de não-preferência para alimentação e/ou antibiose, na época "de primavera". Jaboticabal-SP.

\begin{tabular}{|c|c|c|c|}
\hline Genótipos & $\begin{array}{l}\text { Período de incubação } \\
\text { (dias) }\end{array}$ & Período ninfal (dias) & $\begin{array}{c}\text { Período total de } \\
\text { desenvolvimento (dias) }\end{array}$ \\
\hline LA 716 & $6,1 \pm 0,3 a^{1,2}$ & $11,4 \pm 0,3 a^{1,2}$ & $17,5 \pm 0,4 b^{1,2}$ \\
\hline H. Bruna VFN & $6,0 \pm 0,6 \mathrm{a}$ & $10,4 \pm 0,2 \mathrm{a}$ & $15,7 \pm 0,2 \mathrm{ab}$ \\
\hline PI 127827 & $5,9 \pm 0,1 \mathrm{a}$ & $9,8 \pm 0,4 \mathrm{a}$ & $15,8 \pm 0,6 a b$ \\
\hline PI 134417 & $5,9 \pm 0,1 \mathrm{a}$ & $10,3 \pm 0,5 \mathrm{a}$ & $15,9 \pm 0,4 \mathrm{ab}$ \\
\hline PI 127826 & $5,6 \pm 0,2 \mathrm{a}$ & $9,5 \pm 0,1 \mathrm{a}$ & $15,0 \pm 0,2 \mathrm{a}$ \\
\hline Santa Clara & $5,0 \pm 0,3 \mathrm{a}$ & $10,4 \pm 0,5 \mathrm{a}$ & $15,3 \pm 0,6 \mathrm{a}$ \\
\hline $\mathrm{F}$ & $2,15^{\mathrm{NS}}$ & $2,25^{\mathrm{NS}}$ & $3,21^{*}$ \\
\hline $\mathrm{CV}(\%)$ & 10,54 & 8,04 & 5,61 \\
\hline
\end{tabular}

1. Médias seguidas pela mesma letra não diferem significativamente a $5 \%$ de probabilidade pelo teste de Tukey. ${ }^{2 .}$ Dados originais; (sem transformação). 


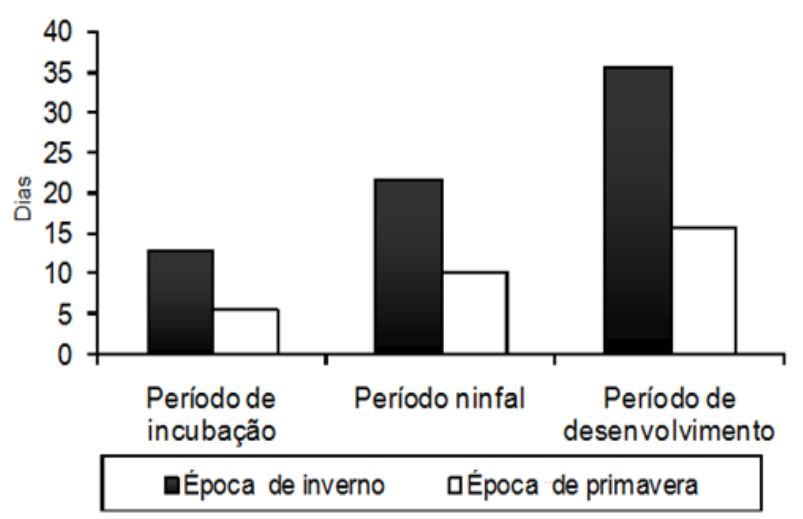

Figura 1. Períodos de incubação, ninfal e desenvolvimento total de B. tabaci biótipo B em diferentes genótipos de tomateiro, nas épocas de "inverno" e de "primavera". Jaboticabal-SP.

O período médio de incubação na época “de inverno" foi de aproximadamente 12,99 dias e de 5,73 dias na época "de primavera" (Figura 1). Oriani e Lara (2000) encontraram valores para esse parâmetro biológico da mosca-branca variando de 7,7 dias na época "das águas" e 13 dias na época "da seca".

$\mathrm{O}$ período ninfal médio encontrado para as duas épocas estudadas (Figura 1) foi 21,77 dias na época de "inverno" e 10,29 dias na época de "primavera", enquanto, o período total de desenvolvimento foi de 35,92 e 15,89 dias, respectivamente. O ciclo do inseto foi 2,26 vezes maior na época de "inverno" em relação à de "primavera", evidenciando ser esta última a mais apropriada ao desenvolvimento do inseto. Estes resultados são semelhantes aos relatados por Silva et al. (2014) que afirmam que o período de temperaturas mais elevadas (normalmente observados na primavera) favorecem o desenvolvimento de B. tabaci Biótipo B, enquanto que as baixas temperaturas observadas na época de "inverno" tendem a alongar o ciclo da praga.

Assim, diante dos resultados encontrados evidenciase a influência da época de cultivo do tomateiro sobre a biologia e desenvolvimento de B. tabaci Biótipo B. Tais informações devem ser consideradas em programas de manejo integrado da praga na cultura.

\section{Conclusões}

A longevidade dos adultos foi maior para os insetos provenientes do genótipo selvagem PI 127826. O ciclo do inseto foi 2,26 vezes maior na época de "inverno" em relação à de "primavera", evidenciando ser esta última a mais apropriada ao desenvolvimento da praga.

\section{Agradecimentos}

Os autores agradecem à Fundação de Amparo à Pesquisa do Estado de São Paulo (FAPESP) pela concessão da Bolsa de Estudo de Doutorado do primeiro autor; ao Dr. André L. Lourenção, do setor de Entomologia do IAC, Campinas, SP, pelo fornecimento da população inicial de mosca-branca; a Dra. Judith Brown (University of Arizona, USA) pela confirmação da população de mosca-branca como sendo o biótipo B.

\section{Referências Bibliográficas}

BALDIN, E. L. L.; VENDRAMIM, J. D.; LOURENÇÃO, A. L. Resistência de genótipos de tomateiro à mosca-branca Bemisia tabaci (Gennadius) biótipo B (Hemiptera: Aleyrodidae). Neotropical Entomology, Londrina-PR, v. 34, n. 3, p. 435-441, 2005.

CARVALHO, S. S.; VENDRAMIM, J. D.; SÁ, I. C. G.; SILVA, M. F. G. F.; RIBEIRO, L. P.; FORIM, M. R. Efeito inseticida sistêmico de nanoformulações à base de nim sobre Bemisia tabaci (Hemiptera: Aleyrodidae) biótipo B em tomateiro. Bragantia, Campinas-SP, v.74, n.3, p. 298-306, 2015.

FANCELLI, M.; VENDRAMIM, J. D. Development of Bemisia tabaci (Gennadius, 1889) biotype B on Lycopersicon spp. genotypes. Scientia Agricola, Piracicaba-SP, v. 59, n. 4, p. $665-669,2002$.

FANCELLI, M.; VENDRAMIM, J. D.; LOURENÇÃO, A. L.; DIAS, C. T. S. Atratividade e preferência para oviposição de Bemisia tabaci (Gennadius) (Hemiptera: Aleyrodidae) biótipo B em genótipos de tomateiro. Neotropical Entomology, Londrina-PR, v. 32, n. 2, p. 319-328, 2003.

FILGUEIRA, F. A. R. Novo manual de olericultura: agrotecnologia moderna na produção e comercialização de hortaliças. Viçosa-MG: UFV, $3^{\mathrm{a}}$ ed., 2008, 421p.

IBGE. INSTITUTO BRASILEIRO DE GEOGRAFIA E ESTATÍSTICA. Levantamento Sistemático da Produção Agrícola. Documento. Brasília: 2016. Disponível em: http://www.sidra.ibge.gov.br/bda/prevsaf/ Acesso em 04 de julho de 2016

LOURENÇÃO, A. L.; NAGAI, H. Surtos populacionais de Bemisia tabaci no Estado de São Paulo. Bragantia, Campinas-SP, v. 53, n. 1, p. 53-59, 1994.

ORIANI, M. A. G.; LARA, F. M. Oviposition preference of Bemisia tabaci (Genn.), biotype B (Homoptera: Aleyrodidae) for bean genotypes containing arcelin in the seeds. Anais da Sociedade Entomológica do Brasil, Londrina-PR, v. 29, n. 3, p. 565-572, 2000.

ORIANI, M. A. G.; LARA, F. M.; BRUNHEROTTO, R. Aspectos biológicos de Bemisia tabaci (Genn.) biótipo B (Hemiptera: Aleyrodidae) em seis genótipos de feijoeiro. Neotropical Entomology, Londrina-PR, v. 37, n. 2, p. 191195,2008

PEIXOTO, M. L.; BOIÇA JÚNIOR, A. L. Antibiose e não preferência para oviposição de Bemisia tabaci (Genn.) biótipo B (Hemiptera: Aleyrodidae) em genótipos de feijoeiro comum. Arquivos do Instituto Biológico, São Paulo-SP, v. 81, n. 2, p. 134-139, 2014. 
SILVA, A. G.; BOIÇA-JÚNIOR, A. L.; FARIAS, P. R. S.; SOUZA, B. H. S.; RODRIGUES, N. E. L.; JESUS, F. G. Dinâmica populacional de mosca-branca Bemisia tabaci (Genn.) Biótipo B (Hemiptera: Aleyrodidae) em feijoeiro. Entomobrasilis, Vassouras-RJ, v.7, n.1, p.5-11, 2014.
VILlAS BOAS, G. V., FRANÇA, F. H., ÁVILA, A. C., BEZERRA, I. C. Manejo integrado da mosca-branca Bemisia argentifolii. Brasília-DF: Embrapa. 1997, 11 p.

VILLAS BOAS, G. L.; FRANCA, F. H.; MACEDO, N. Potencial biótico da mosca-branca Bemisia argentifolii a diferentes plantas hospedeiras. Horticultura Brasileira, Brasília-DF, v. 20, n. 1, p.71-79, 2002. 